\title{
CULTIVATION CONDITIONS AND EXPRESSION OF "FRUCTOSE EFFECT" IN ACTINOMYCES ROSEOFLAVUS VAR. ROSEOFUNGINI
}

\author{
EKATERINA T. NIKITINA* AND L.V. KALAKOUTSKII** \\ * Institute of Microbiology and Virology, Kasakh Academy of \\ Sciences, Alma-Ata, USSR \\ ** Institute of Microbiology, USSR Academy of Sciences, \\ Moscow, USSR
}

(Received June 14, 1972)

Actinomyces (Streptomyces) roseoflavus var. roseofungini which yields secondary nocardioform colonies when grown on synthetic medium with Dfructose as sole carbon and energy source ("fructose effect") was employed as test organism in screening for conditions and compounds which enhance or retard the fructose effect.

The results of alterations in cultivation conditions point to the importance of fructose being metabolized for its effect to be observed. The effective individual compounds tested were tentatively grouped as follows: (1) Strong1y inhibitory in high concentrations for the growth of actinomycete while retarding emergence of secondary colonies against the background of weak growth in moderate or low concentrations (most antibiotics and some enzyme inhibitors, phenol, indole, anthranillic acid, indolyl-acetic acid, sodium hydrosulphite, iron salts). (2) Non-inhibitory for growth (occasional stimulation noted), retarding emergence of secondary colonies. a) Active in low concentrations (mannitol, tyrosine, shikimate, oxalate, alanine, valine, norvaline, leucine). b) Active in high concentrations (glucose, galactose, glycerol, ascorbate, citrate, lactate, several amino acids). (3) Non-inhibitory for growth with slight tendency to enhance emergence of secondary colonies (fumarate, malate, succinate, phenylalanine, sodium chloride). Compounds of group 3 neither individually nor in combinations were able to substitute fructose in its capacity to elicit secondary growth. Some treatments (increase in incubation temperature, addition of methionine) tended to increase the relative number of secondary colonies of diminished size.

The results are discussed in relation to the possibility that emergence of secondary colonies is due to some "abnormalities" in fructose metabolism, leading to production of metabolites which induce and/or select particular type of mutants. Among effective additives some (mannitol) probably affect the fructose metabolism itself, while others "cure" the lesions due to its "peculiarity" or improve the efficiency of fructose utilization. 
When Actinomyces (Streptomyces) roseoflavus var. roseofungini as well as some other actinomycetes are cultured on synthetic media with D-fructose as a sole carbon and energy source, they respond in a peculiar manner by forming secondary colonies of nocardioform variants (mutants) within primary "normal" colonies. Our previous communications dealt with some aspects of the phenomenon $(2-4)$.

The remarkable specificity of fructose-containing media to elicit peculiar response in actinomycetes warranted a more thorough study on the effect of cultivation conditions on the expression of the phenomenon tentatively called the "fructose effect". To start with, we attempted a rough screening for conditions and compounds which, in some way, interfere with "fructose effect" (that is, eliminate or enhance it). Some of the likely possibilities were subjected to experimental scrutiny and discussed.

\section{MATERIALS AND METHODS}

The strain, Act. (Str.) roseoflavus var. roseofungini, from the collection of Institute of Microbiology and Virology of the Kasakh Academy of Sciences. in Alma-Ata was used throughout this study. This actinomycete was chosen because it was the first in which unusual response to cultivation on fructosecontaining media was observed. In this strain the secondary nocardioform colonies were rather abundant, characteristically pigmented and easily recognized when plate- or tube-cultures were examined visually or with the help of a magnifying glass for their appearance (Fig. 1).

A loopful of spores from 7-day-old cultures was dispersed on the surface of agar slants in standard test-tubes, each containing $5 \mathrm{ml}$ of PRIDHAM and GotTlieB's (5) synthetic medium with $1 \%(\mathrm{w} / \mathrm{v})$ of $\mathrm{D}$-fructose. The slants (in triplicate for each test) were then incubated at $28^{\circ}$ for 30 days in a thermostat with controlled humidity. At desired time intervals the test-tubes were removed and inspected for the appearance of secondary colonies within "normal" colonies of the actinomycete with the help of a magnifying glass. The mean relative numbers of secondary colonies per slant as well as the earliest time of their appearance (in terms of days of incubation) were recorded along with qualitative assessment of the actinomycete's growth pattern and intensity.

Different substances (individually or in combinations) were added to the chemically defined basal medium with D-fructose in graded series of concentrations. Sugars, organic and amino acids were sterilized separately in Koch's sterilizer as concentrated neutral solutions. Ferric chloride solutions, enzyme inhibitors, antibiotics, and some of the other substances were sterilized by Seitz filtration. Most of the reagents used were of the reagent grade.

On addition of test substances $\mathrm{pH}$ of the media was adjusted at the level of that of the control medium.

Some other details of experimental procedures are given in the text. 

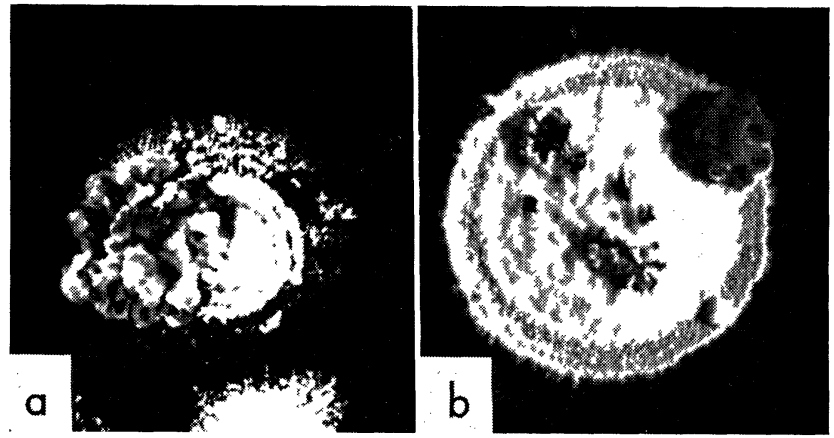

Fig. 1. Different types of secondary nocardioform colonies emerging on parental "normal" colonies of Act. roseoflavus var. roseofungini cultivated on Pridham and Gottlieb's synthetic medium with D-fructose as a sole carbon and energy source. $\times 5$

Each series of experiments was repeated at least 3 times and mean data are presented.

\section{RESULTS}

\section{Effect of cultivation conditions}

It seemed likely that actinomycetes growing on a fructose-containing medium might respond in a peculiar manner (emergence of secondary colonies of stable nocardioform variants) by either of the two possibilities: (a) Chemical conditions which arise due to the presence of fructose in the media, sugar impurities, or its transformations during medium preparation, heating, etc. (b) Chemical factor(s) which arise because of fructose being metabolized by the actinomycete and which, once appearing, induce and/or select particular type of variants (mutants). An attempt was made to discriminate between these possibilities.

It is generally known that $D$-fructose is a rather unstable and reactive compound. Fructose solutions prior to their addition to the mineral saltagar base were subjected to excessive heating at various $\mathrm{pH}$. The results (Table 1) suggest that pre-heating of fructose solutions at physiological $\mathrm{pH}$ does not alter the sugar sufficiently to cause significant changes in the response of the actinomycete.

Fructose possesses the ability to chelate with certain metal ions and iron in particular $(6,7)$. There was thus a possibility that the sugar affects the growth of actinomycete through iron limitation. However, addition of extra quantities of either ferric-chloride $(0.002-0.015 \%, \mathrm{w} / \mathrm{v})$ or ferric citrate $(0.03$ $-0.25 \%, \mathrm{w} / \mathrm{v})$ to the basal medium failed to affect significantly the relative number of secondary colonies and the rate of their emergence. 
Table 1. Effect of preheating of fructose solutions on the expression of "fructose effect" in Act. roseoflavus var. roseofungini.

\begin{tabular}{c|c|c|c|c|c}
\hline $\begin{array}{c}\text { Initial pH } \\
\text { of fructose } \\
\text { solution }\end{array}$ & $\begin{array}{c}\text { Time of heat- } \\
\text { ing at 100 } \\
\text { (min) }\end{array}$ & $\begin{array}{c}\mathrm{pH} \text { after } \\
\text { heating }\end{array}$ & $\begin{array}{c}\text { Color of the } \\
\text { solution after } \\
\text { heating }\end{array}$ & $\begin{array}{c}\text { Secondary } \\
\text { colonies } \\
\text { formed }\end{array}$ & $\begin{array}{c}\text { Growth } \\
\text { intensity }^{c}\end{array}$ \\
\hline 3.0 & 60 & 3.0 & yellowish & $7 / 15$ & 3 \\
7.0 & 60 & 6.0 & $\prime \prime$ & $8 / 14$ & 3 \\
8.0 & 60 & 6.0 & $\prime \prime$ & $7 / 12$ & 3 \\
10.0 & 60 & 7.0 & rose-brown & n.f. ${ }^{d}$ & 2 \\
6.0 & $\begin{array}{c}\text { No heating } \\
\text { (control) }\end{array}$ & 6.0 & yellowish & $6 / 11$ & 3 \\
\hline
\end{tabular}

a $40 \%(\mathrm{w} / \mathrm{v})$ solutions of $\mathrm{D}$-fructose in distilled water were adjusted to desired $\mathrm{pH}$ levels and heated in a boiling water bath. The resulting $\mathrm{pH}$ of the solutions were measured and their colors assessed visually. Then $\mathrm{pH}$ of solutions were readjusted to $\mathrm{pH}$ 6.0, solutions sterilized, and added aseptically to the agarized mineralbase medium in a final concentration of $1 \%(\mathrm{w} / \mathrm{v})$.

$b$ The numerator expresses the earliest time (days of incubation) when secondary colonies first appear, and the denominator, the mean number of secondary colonies per slant at the end of incubation.

$c$ Growth intensity assessed visually at the end of incubation period: 0 , no growth; 4, abundant growth.

d Secondary colonies not formed at all.

Commercially available fructose of different batches (with presumably variable amounts of different impurities) produced rather similar effect in actinomycete test system.

The above findings together with those shown in Table 2 as well as our earlier observations $(1,2)$ on the occurrence of a quite definite lag in the emergence of secondary colonies suggested that the chemical conditions in the medium due to fructose presence were not primarily responsible for the observed anomalies in the actinomycete behaviour.

\section{Effect of complex and individual additives}

Earlier experiments (1) showed that "fructose effect" can be observed on several synthetic media with either nitrate or ammonium as the nitrogen source. However, some of the attempts to reproduce it on complex organic media with fructose failed. In subsequent experiments, therefore, some complex organic constituents in varying concentrations were added to the basal mineral salt-fructose medium.

As one may see from data presented in Table 3, peptone, casein hydrolyzate, and Hottinger's extract were rather effective in high concentrations in retarding the emergence of secondary colonies. This led us to the systematic screening for individual compounds effective in the particular test 
Table 2. Effect of varying cultural conditions on the emergence of secondary colonies of Act. roseoflavus var. roseofungini on Pridham and Gottlieb's synthetic medium with fructose.

\begin{tabular}{|c|c|c|c|}
\hline Variable & Range & $\begin{array}{c}\text { Secondary } \\
\text { colonies formed }\end{array}$ & $\begin{array}{l}\text { Growth } \\
\text { intensity }{ }^{c}\end{array}$ \\
\hline \multirow[t]{5}{*}{ Fructose concn. } & $\begin{array}{l}1.0 \%, \mathrm{w} / \mathrm{v} \\
\text { (control) }\end{array}$ & $6 / 14$ & 3 \\
\hline & 2.25 & $6 / 6$ & 3 \\
\hline & 3.5 & $6 / 4$ & $2-3$ \\
\hline & 6.0 & $18 / 1$ & 2 \\
\hline & 10.0 & n.f. ${ }^{d}$ & $1-2$ \\
\hline \multirow[t]{2}{*}{ Temperature } & $28^{\circ}$ (control) & $6 / 14$ & 3 \\
\hline & $37^{\circ}$ & $5 / 34^{e}$ & $2-3$ \\
\hline \multirow{7}{*}{$\begin{array}{l}\text { Initial } \mathrm{pH} \text { of the } \\
\text { medium }\end{array}$} & 3.0 & & 0 \\
\hline & 4.0 & & 0 \\
\hline & 6.0 & n.f. & $1-2$ \\
\hline & 7.0 (control) & $7 / 12$ & 3 \\
\hline & 8.0 & $10 / 12$ & $2-3$ \\
\hline & 8.5 & $15 / 14$ & $2-3$ \\
\hline & 9.0 & & 0 \\
\hline \multirow{4}{*}{$\begin{array}{l}\text { Relative humidity } \\
\text { (in desiccators over) }\end{array}$} & $\mathrm{H}_{2} \mathrm{O}$ (control) & $5 / 16$ & $3-4$ \\
\hline & $\mathrm{H}_{2} \mathrm{SO}_{4}$ (sp. gr. 1. 33)f & $6 / 14$ & 3 \\
\hline & $\mathrm{H}_{2} \mathrm{SO}_{4}$ (sp. gr. 1. 49) & $6 / 10$ & 3 \\
\hline & $\mathrm{H}_{2} \mathrm{SO}_{4}$ (conc.) & $6 / 4$ & 2 \\
\hline \multirow[t]{4}{*}{ Agar concentration } & $1.0 \%(\mathrm{w} / \mathrm{v})$ & $6 / 19$ & $3-4$ \\
\hline & 2.0 (control) & $6 / 16$ & 3 \\
\hline & 4.0 & $7 / 12$ & 3 \\
\hline & 7.0 & $7 / 10$ & $2-3$ \\
\hline
\end{tabular}

$b, c, d$ Same as in Table 1.

$e$ although the relative number of secondary colonies increased appreciably, the mean diameter of secondary colonies diminished significantly.

$f$ sp. gr., specific gravity of $\mathrm{H}_{2} \mathrm{SO}_{4}$ soln.

system. Results of experiments of this kind are summarized in Table 4, and the effect of some inhibitors in Table 5. It looks as if conditions and compounds found to interfere in some way with emergence of secondary colonies on fructose-containing medium could be tentatively grouped as follows.

1. Those strongly inhibiting growth of the parent actinomycete culture when applied at the extremes or in high concentrations. At lower concentrations emergence of secondary colonies was inhibited against a background of restricted growth of the actinomycete. Most inhibitors, $\mathrm{pH}$ and relative humidity extremes produced the effect. One should also list here phenol, 
Table 3. Effect of adding complex organic nutritives to the mineral salt-fructose medium on the expression of "fructose effect" in Actinomyces roseoflavus var. roseofungini.

\begin{tabular}{|c|c|c|c|c|c|c|c|}
\hline \multirow{3}{*}{ Additives } & \multicolumn{6}{|c|}{ Final concn. of the additives, $\% \%, \mathrm{w} / \mathrm{v}$} & \multirow{3}{*}{$\begin{array}{c}\text { Growth }{ }^{c} \text { in } \\
\text { presence } \\
\text { of } \\
\text { additives }\end{array}$} \\
\hline & 1.0 & 0.5 & 0.25 & 0.125 & 0.062 & 0.031 & \\
\hline & \multicolumn{6}{|c|}{ Secondary colonies formed ${ }^{b}$} & \\
\hline Soybean meal & $8 / 10$ & $8 / 8$ & $8 / 10$ & $8 / 11$ & $8 / 11$ & $8 / 12$ & 4 \\
\hline Fish meal & $8 / 8$ & $8 / 12$ & $8 / 11$ & $8 / 13$ & $8 / 14$ & $8 / 15$ & 4 \\
\hline Corn meal & $8 / 10$ & $8 / 13$ & $9 / 15$ & $9 / 15$ & $9 / 14$ & $9 / 16$ & 4 \\
\hline Peptone & n.f. ${ }^{d}$ & $8 / 2$ & $8 / 3$ & $8 / 5$ & $8 / 9$ & $8 / 14$ & 4 \\
\hline Casein hydrolyzate & n.f. & $8 / 1$ & $8 / 2$ & $8 / 4$ & $8 / 6$ & $8 / 12$ & 4 \\
\hline Hottinger's extract & n.f. & $10 / 2$ & $9 / 4$ & $8 / 9$ & $8 / 12$ & $8 / 15$ & 4 \\
\hline Yeast extract & $8 / 10$ & $8 / 11$ & $8 / 12$ & $8 / 14$ & $8 / 14$ & $8 / 15$ & 4 \\
\hline Control (no addn.) & & & & & & & 3 \\
\hline
\end{tabular}

$b, c, d$ Same as in Table 1 . Growth intensity assessed at highest concn. of additives tested.

anthranilic acid, indolylacetic acid, high concentrations of iron salts, and sodium hydrosulphite. The rise in incubation temperature (Table 2) seems to be an exception here.

In commenting upon possible role of the above conditions and compounds one might consider the possibility of decrease in cell populations serving for selection of particular kind of mutants.

2. Compounds and conditions which bo not affect appreciably the growth of the actinomycete (stimulation in some cases possible) but eliminate or delay the emergence of secondary colonies against this background.

a) Effective in this capacity in relatively low concentrations: Mannitol, oxalate, alanine, leucine, valine, norvaline, tyrosine, and shikimic acid. Further analysis of their activity seems particularly interesting in view of their "specificity" and probable absence of side effects.

b) Effective only in relatively high concentrations: Glucose, galactose, glycerol, ascorbate, lactate, some of the amino acids, and complex organic extracts. Some of the amino acids (Table 3) just delay the emergence of secondary colonies and occupy intermediate position between $2 \mathrm{a}$ and $\mathrm{b}$.

3. Compounds and conditions which do not affect growth to a large extent, but seem to slightly enhance the emergence of secondary colonies: Fumarate, succinate and malate, phenylalanine, sodium chloride.

Some of the compounds (notably methionine) tended to increase the mean relative number of secondary colonies per slant. So did the increase in the incubation temperature. Similar but less evident effect was observed also with glycine, aspartic and nicotinic acids, sorbitol, and glycerol (in lower con- 
Table 4. Effect of adding some individual compounds to mineral salts-fructose medium on emergence of secondary colonies in Act. roseoflavus var. roseofungini.

\begin{tabular}{|c|c|c|c|c|c|c|c|c|}
\hline \multirow{3}{*}{$\begin{array}{l}\text { Compound } \\
\text { added }\end{array}$} & \multicolumn{6}{|c|}{ Final concn. of additives $\% \%, \mathrm{w} / \mathrm{v}$} & \multirow{2}{*}{\multicolumn{2}{|c|}{$\begin{array}{l}\text { Growth }{ }^{c} \text { on } \\
\text { Pridham and } \\
\text { Gottlieb's } \\
\text { medium in } \\
\text { presence of } \\
\text { compound } \\
\text { added }\end{array}$}} \\
\hline & 1.0 & 0.5 & 0.25 & 0.125 & 0.062 & 0.031 & & \\
\hline & \multicolumn{6}{|c|}{ Emergence of secondary colonies ${ }^{b}$} & \multicolumn{2}{|c|}{$\begin{array}{l}\text { with } 1 \% \text { without } \\
\text { (w/v) } \text { fructose } \\
\text { fructose }\end{array}$} \\
\hline 1 & 2 & 3 & 4 & 5 & 6 & 7 & 8 & 9 \\
\hline \multicolumn{9}{|l|}{ Sugars } \\
\hline D-Glucose & n.f. ${ }^{d}$ & $10 / 3$ & $9 / 8$ & $8 / 7$ & $7 / 9$ & $7 / 12$ & 3 & 3 \\
\hline D-Galactose & n.f. & $15 / 1$ & $15 / 1$ & $15 / 2$ & $8 / 6$ & $8 / 12$ & 3 & 3 \\
\hline L-Sorbose & $11 / 3$ & $11 / 8$ & $11 / 9$ & $11 / 11$ & $6 / 12$ & n.t. ${ }^{e}$ & $4^{f}$ & 1 \\
\hline \multicolumn{9}{|l|}{ Alcohols } \\
\hline Ethanol & $8 / 12$ & $8 / 7$ & $7 / 8$ & $7 / 10$ & $7 / 12$ & n.t. & 4 & 2 \\
\hline Glycerol & n.f. & $9 / 15$ & $7 / 7$ & $7 / 20$ & $7 / 16$ & n.t. & 4 & 4 \\
\hline Mannitol & n.f. & n.f. & n.f. & n.f. & n.f. & n.f. & $4^{h}$ & 4 \\
\hline Sorbitol & $15 / 9$ & $11 / 22$ & $11 / 22$ & $15 / 20$ & $15 / 19$ & $11 / 16$ & $3^{f}$ & 1 \\
\hline Inositol & $8 / 1$ & $8 / 1$ & $8 / 2$ & $8 / 2$ & $15 / 1$ & $15 / 1$ & 3 & 1 \\
\hline Dulcitol & $11 / 4$ & $11 / 6$ & $11 / 14$ & $11 / 14$ & $15 / 14$ & $15 / 11$ & 3 & 1 \\
\hline \multicolumn{9}{|l|}{$\begin{array}{l}\text { Salts of organic } \\
\text { acids }\end{array}$} \\
\hline $\mathrm{Na}$ acetate & $10 / 6$ & $10 / 8$ & $10 / 11$ & $8 / 22$ & $6 / 13$ & $8 / 12$ & 3 & 3 \\
\hline $\mathrm{Na}$ pyruvate & $10 / 5$ & $10 / 7$ & $10 / 9$ & $8 / 9$ & $6 / 11$ & $6 / 11$ & 3 & 2 \\
\hline $\mathrm{Na}$ citrate & n.f. & n.f. & $15 / 7$ & $15 / 8$ & $15 / 9$ & $8 / 12$ & 4 & 4 \\
\hline $\mathrm{Na}$ malate & $6 / 1$ & $6 / 2$ & $3 / 2$ & $3 / 7$ & $3 / 9$ & $6 / 11$ & 3 & 2 \\
\hline $\mathrm{Na}$ succinate & $5 / 2$ & $5 / 3$ & $6 / 5$ & $3 / 6$ & $6 / 5$ & $5 / 9$ & 3 & 2 \\
\hline $\mathrm{Na}$ fumarate & $6 / 1$ & $3 / 2$ & $3 / 3$ & $3 / 7$ & $5 / 7$ & $5 / 11$ & 3 & 2 \\
\hline $\mathrm{Na}$ oxalate & n.f. & n.f. & n.f. & n.f. & $15 / 2$ & $8 / 1$ & $3^{h}$ & 1 \\
\hline $\mathrm{NH}_{4}$ oxalate & n.f.g & n.f. & n.f. & n.f. & n.f. & $15 / 1$ & $3^{h}$ & 1 \\
\hline Na lactate & n.f. & $8 / 2$ & $8 / 10$ & $8 / 6$ & $8 / 4$ & $6 / 6$ & 3 & 1 \\
\hline Ca lactate & n.f. & $15 / 3$ & $12 / 3$ & $11 / 5$ & $11 / 9$ & $8 / 11$ & 3 & 1 \\
\hline $\mathrm{Na}$ tartrate & $15 / 1$ & $15 / 3$ & $15 / 8$ & $8 / 3$ & $8 / 4$ & $11 / 6$ & 3 & 1 \\
\hline $\mathrm{Na}$ ascorbate & $18 / 4$ & $15 / 10$ & $11 / 14$ & $11 / 25$ & $11 / 18$ & $8 / 20$ & 3 & n.t. \\
\hline \multicolumn{9}{|l|}{$\begin{array}{l}\text { Amino acids and } \\
\text { derivatives }\end{array}$} \\
\hline Glycine & $15 / 2$ & $10 / 4$ & $10 / 22$ & $10 / 20$ & $10 / 20$ & n.t. & 3 & 2 \\
\hline DL- $\alpha$-Alanine & n.f. & n.f. & n.f. & n.f. & $15 / 2$ & $8 / 7$ & 4 & 3 \\
\hline
\end{tabular}


Table 4. (Continued)

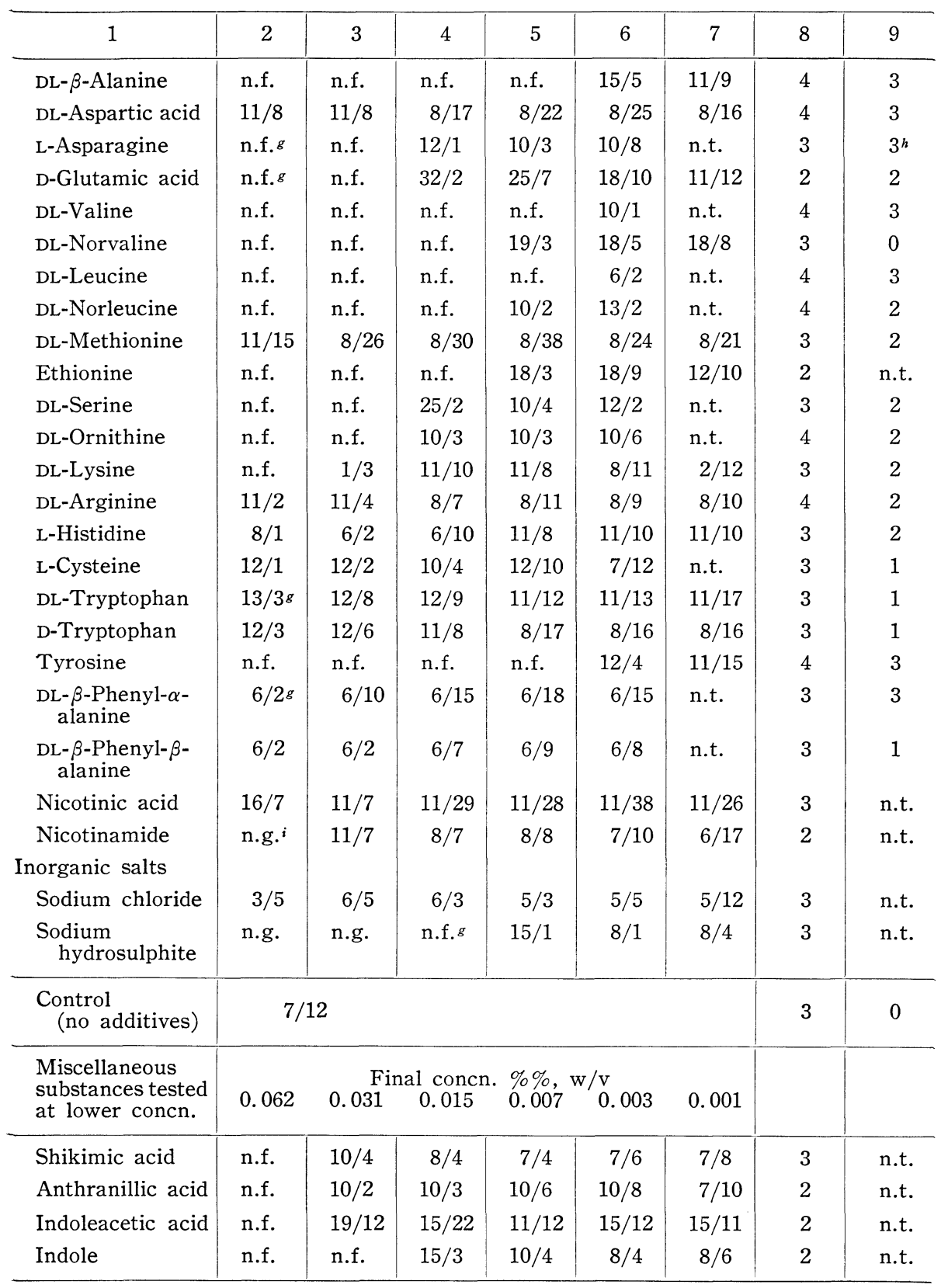

$b, c, d$ Same as in Table 1 and 2 . Growth recorded at highest concn. of additives permissible for growth. 
Table 5. Effect of some inhibitors on growth of Act. roseoflavus var. roseofungini and emergence of secondary colonies on Pridham and Gottlieb's synthetic medium with $1 \%(\mathrm{w} / \mathrm{v})$ of fructose.

\begin{tabular}{|c|c|c|c|c|}
\hline \multirow[b]{2}{*}{ Inhibitor } & \multirow[b]{2}{*}{ Concn. range tested } & \multicolumn{2}{|c|}{ Lowest concn. } & \multirow[b]{2}{*}{$\begin{array}{l}\text { Kind of } \\
\text { effect }^{a} \\
\text { observed }\end{array}$} \\
\hline & & $\begin{array}{l}\text { permitting } \\
\text { visible } \\
\text { growth }\end{array}$ & $\begin{array}{c}\text { affecting } \\
\text { emergence } \\
\text { of sec. } \\
\text { colonies }\end{array}$ & \\
\hline Phenol & $2 \cdot 10^{-1}-2 \cdot 10^{-4} \%(\mathrm{w} / \mathrm{v})$ & $10^{-1}$ & $3 \cdot 10^{-3}$ & - \\
\hline 2, 4-Dinitrophenol & $10^{-1}-10^{-10}$ & $10^{-6}$ & $10^{-7}$ & - \\
\hline $\mathrm{Na}$ arsenite & $10^{-1}-10^{-6}$ & $10^{-3}$ & $10^{-3}$ & 0 \\
\hline $\mathrm{Na}$ arsenate & $10^{-1}-10^{-6}$ & $10^{-3}$ & $10^{-3}$ & 0 \\
\hline $\mathrm{Na}$ fluoroacetate & $10^{-1}-10^{-6}$ & $10^{-1}$ & $10^{-1}$ & 0 \\
\hline Chloramphenicol & $1 \cdot 10^{0}-7 \cdot 10^{-4} \mu \mathrm{g} / \mathrm{ml}$ & $7 \cdot 10^{-3}$ & $3 \cdot 10^{-3}$ & - \\
\hline Streptomycin & $\|\quad\|$ & $3 \cdot 10^{-2}$ & $7 \cdot 10^{-3}$ & - \\
\hline Kanamycin & /1 & $3 \cdot 10^{-3}$ & $7 \cdot 10^{-4}$ & - \\
\hline Chlortetracycline & $10^{3}-10^{0}(\mathrm{U} / \mathrm{ml})$ & $1.5 \cdot 10$ & $0.4 \cdot 10$ & - \\
\hline Oxytetracycline & "I $\quad 11$ & $6.2 \cdot 10$ & $0.8 \cdot 10$ & - \\
\hline Erythromycin & $\|\quad\| \quad \|$ & $5.0 \cdot 10^{2}$ & $6.2 \cdot 10$ & - \\
\hline Roseofungin $^{b}$ & $1 \cdot 10^{-1}-1 \cdot 10^{-3} \%(\mathrm{w} / \mathrm{v})$ & $6 \cdot 10^{-2}$ & $6 \cdot 10^{-2}$ & - \\
\hline
\end{tabular}

a - , emergence of secondary colonies inhibited; 0 , no specific effect observed.

$b$ This antifungal antibiotic is produced by parent culture of Act. roseoflavus var. roseofungini and (in increased titers) by its nocardioform "fructose" variant.

centrations). Most of the other substances tended to decrease the mean relative number of secondary colonies.

An important basic feature of all the treatments tried was the fact that their effect was always phenotypic. That is, on subsequent cultivation of the parent strain on fructose-containing medium under standard conditions and without the additives the emergence of secondary colonies could be observed again.

It should be noted that nocardioform colonies of Act. roseoflavus var. roseofungini (fructose variant) were usually yellow colored, the pigment being probably associated with antibiotic activity. Colorless secondary colonies

e n.t., not tested.

$f$ Production of brownish pigment noted.

$g$ Growth retarded at higher concn.

$h$ Colonies of the actinomycete assumed more compact form.

$i$ n.g., no growth at this concn. 
rarely arose. These were of two kinds; those which assumed yellow color in subsequent transfers, and those which remained colorless. When amino acids were added to the mineral salt-fructose medium, the relative number of colorless secondary colonies tended to increase with the following substances (range of concn. given in $\% \%, \mathrm{w} / \mathrm{v})$ : Alanine $(0.62)$; glycine $(0.03-1.0)$; DLvaline $(0.062)$; DL-leucine $(0.062)$; DL-norleucine $(0.062-0.125) ;$ DL-arginine $\cdot \mathrm{HCl}$ (0.062-0.125); DL-methionine (0.031-1.0); DL-lysine (0.125-0.5); L-histidine. $\mathrm{HCl}(0.125-1.0)$; DL-tryptophan (0.125-1.0); D-tryptophan (0.125-1.0); DL- $\beta$ phenyl- $\alpha$-alanine $(0.5-1.0)$; DL- $\beta$-phenyl- $\beta$-alanine $(0.5-1.0)$. The relative number of colorless colonies increased also with glycerol $(0.25-0.5)$. It should be noted that colorless colonies formed in the presence of valine, histidine, norleucine, and methionine on subsequent transfers gave yellow-colored colonies. Thus the effect of last amino acids was strictly phenotypic.

\section{DISCUSSION}

Most of the data tend to emphasize the intimate connection between the fructose metabolism in the actinomycete and the origin of secondary mutant colonies.

Many substances listed above under $(2 \mathrm{~b})$ are readily metabolized by the actinomycete as a sole carbon and energy source. Their retarding effect might be attributed to their competition with fructose, the delay in the utilization of the latter due to the well-known "diauxie" phenomenon. Apart from sugars and glycerol, one might consider a similar role for high concentrations of citrate and some amino acids, like alanine, glutamic and aspartic acids, valine, leucine, tyrosine, and asparagine. It should be stressed, however, that not all readily utilizable compounds eliminate the "fructose effect", as seen in the case of acetate. The stereoisomer of fructose, L-sorbose, was not utilized and had no activity. The same was true for sorbitol, which is the stereoisomer of mannitol.

The fact that mannitol was active in rather low concentrations is particularly interesting. From what is known of the metabolism of this compound in other bacteria (see, for instance, 8 ) and actinomycetes ( 9 ), mannitol might conceivably affect the early steps of fructose utilization. Some of the organic acids, notably oxalate and possibly lactate, are likely candidates for affecting later steps of fructose utilization. It might be mentioned that both these compounds are not the tricarboxylic acid cycle intermediates. Both these compounds were not actively utilized as a sole carbon source by the actinomycete.

The compounds listed in group 3 were examined individually and in various combinations for their ability to substitute for fructose in the capacity to cause emergence of secondary colonies on Pridham and Gottlieb's synthetic medium. The results were negative.

Relatively frequent incidence of activity among amino acids suggests a 
connection between supposed "abnormalities" in fructose metabolism and amino acids (possibly protein) biosynthesis.

Several of the active amino acids were monoamino-monocarboxylic acids. The general assumption might be that when added to the culture medium these compounds serve as the sources of metabolites which become limited when fructose is utilized as a sole source of carbon and energy. Such an assumption might at least partially explain the earlier reported differences (2) in response of various strains of actinomycetes to cultivation on fructosecontaining medium by different levels of amino acid production and accumulation.

An alternative role for amino acids would be the inactivation of some biologically active compound(s) produced in the course of fructose metabolism.

The positive effect of methionine ( $c f$. the reverse activity of ethionine and norleucine) was probably not related to sulfur, since cysteine had no such activity. Although tryptophan and phenylalanine proved to be rather inactive in affecting "fructose effect," some of the intermediates of tryptophan biosynthesis and its possible transformation products appeared to have a significant activity. This reminds of the effect of tryptophan and niacin in mammals fed with fructose (10), where these compounds seemed to improve significantly the efficiency of fructose utilization.

It is not clear at present what kind of metabolic lesions are significant in relation to the "fructose effect." Secondary nocardioform colonies in Act. roseoflavus var. roseofungini arize within primary colonies. This suggests that the secondary colonies are formed under restricted oxygen supply. Some of the compounds tested are known to affect significantly the redox potential of culture media. However, considerations of results with such substances as sodium hydrosulphite, ascorbate, and cysteine do not support the suggestion that redox potential of cultivation medium is of special importance for the expression of "fructose effect."

The difference in concentration of phenol for growth inhibitory and secondary colony-retarding activities is worth mentioning. More specific activity of this compound might not be excluded, since other authors (11) showed the inhibition of cell division by phenol in some Nocardia spp.

In conclusion, one is left with the impression that emergence of secondary (mutant) colonies seems to be related to some peculiarities of fructose metabolism leading to production of substances which induce and/or select particular kind of mutants. Among the effective additives tested, some (mannitol) probably affect the fructose metabolism itself, while others (amino acids) "cure" the metabolic lesions due to its peculiarity or improve the efficiency of fructose utilization. Although $\mathrm{D}$-fructose belongs to sugars most widely utilized by actinomycetes (5) it is clear that much information is needed to understand peculiarity of its metabolism in these organisms. 


\section{REFERENCES}

1) E.T. Nikitina, G.G. Kasakova, and L.V. Kalakoutskil, Dokl. Acad. Nauk, S.S.S.R., 196, 448 (1971).

2) E.T. Nikitina and L.V. Kalakoutskiı, Z. Allg. Mikrobiol., 11, 601 (1971).

3) N.E. Cherny, A.S. Tikhonenko, E.T. Nikitina, and L.V. Kalakoutskil, Cytobios., 5, 7 (1972).

4) N.E. Cherny, A.S. Tikhonenko, E.T. Nikitina, and L.V. Kalakoutskil, Cytobios., 5, 101 (1972).

5) T. Pridham and D. Gottlieb, (J. Bacteriol.) Bacteriology, 56, 107 (1948).

6) P.D. Saltman and P.I. Charley, U.S. Pat. 3,074,927. Cited by G.E. Ward in Microbial Technology, ed. by H.J. Peppler, Reinhold Publishing Co., New YorkAmsterdam-London, (1967), pp. 200-221.

7) P.S. Davis and D.J. Deller, Nature, 212, 404 (1966).

8) W.B. Moore and C. Rainbow, J. Gen. Microbiol., 13, 190 (1955).

9) P.R. MAURER and R.D. BATt, J. Bacteriol., 83, 1131 (1962).

10) K.M. Hundley, cited by H.G. Day and W. Pigman in The Carbohydrates, ed. by W. Pigman, Academic Press Inc., New York, (1957) pp. 180-189.

11) S. Watanabe, A. Kumagata, and H. Murooka, J. Gen. Appl. Microbiol., 9, 363 (1963). 